\section{Controle e Cerimônia: o inquérito policial em um sistema de justiça criminal frouxamente ajustado ${ }^{1}$}

Joana Domingues Vargas ${ }^{2}$ Juliana Neves Lopes Rodrigues ${ }^{3}$

Resumo: Este artigo parte da hipótese de que o Sistema de Justiça Criminal brasileiro é frouxamente articulado e que o inquérito policial, por ser obrigatório, cumpre a função de estabelecer algum grau de coordenação das atividades realizadas na organização policial e entre as organizações do Sistema de Justiça Criminal (SJC). A validade desse instrumento passa a ser questionada quando a crença na capacidade do Estado de controlar o crime é fortemente abalada e substituída por demandas de eficiência e de maior articulação na administração da justiça. Apesar do desejo de mudança, diversos fatores concorrem para a manutenção desse modelo de investigação.

Palavras-chave: Inquérito Policial, Sistema de Justiça Criminal, Polícia, Teoria das organizações.

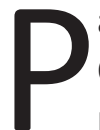

ara que serve o inquérito policial? Ele deve ou não continuar a existir? Questões como essas são, hoje, particularmente polêmicas e encontram partidários fervorosos, tanto entre os que são favoráveis à sua manutenção, quanto entre os defensores da sua extinção.

Iremos em outra direção. A nossa hipótese, a ser demonstrada nesse texto, é a de que o inquérito policial, por ser obrigatório, permite o estabelecimento de algum grau de articulação das atividades realizadas na organização policial e entre as organizações do Sistema de Justiça Criminal (SJC), tornando-o frouxamente ajustado. Mas a validade desse instrumento passa a ser questionada quando a crença na capacidade do Estado de controlar o crime é fortemente abalada e substituída por demandas de eficiência e de maior articulação na administração da justiça.

O que é o inquérito policial?

O inquérito policial reúne os resultados da investigação transpostos para a lógica
Recebimento:

10.11.2010

1. Este artigo é resultado de reflexões realizadas com base em material levantado para a pesquisa $O$ Inquérito Policial no Brasil: Uma pesquisa empírica - o caso de Belo Horizonte, coordenada por Joana D. Vargas, bem como em material advindo de um de seus desdobramentos, a pesquisa que deu origem à dissertação de mestrado intitulada Inquérito Policial: inquisitorialidade e formação de culpa de homicídios dolosos, de Juliana N. L. Rodrigues. Nossos agradecimentos à Federação Nacional de Policiais Federais (FENAPEF) que financiou a pesquisa nacional O Inquérito Policial no Brasil: uma pesquisa empírica e ao seu coordenador, Michel Misse. Agradecemos também ao Arthur Trindade Costa, responsável pela organização desse Dossiê, pela oportunidade e paciência, e à Klarissa Almeida Silva, pelos comentários ao texto.

2. Doutora em Sociologia (IUPERJ) Professora Adjunta do NEPP-DH da UFRJ. Professora Colaboradora do Programa de Pós -Graduação em Sociologia da UFMG. 
Pesquisadora do NECVU/UFRJ

E-mail: jovargas@ uol.com.br

3. Mestre em Sociologia (UFMG)

E-mail: julianajnlr@ gmail.com e linguagem jurídicas, consistindo em um documento escrito e obrigatório previsto pelo Código de Processo Penal brasileiro. Nele, encontram-se agrupados, dentre outros: o registro da ocorrência realizado por policiais militares; laudos e exames confeccionados por peritos; ordens de serviços cumpridas por investigadores; depoimentos transcritos por escrivães; portarias e relatórios de delegados; manifestações de promotores, solicitando novas investigações ou autorizando a dilatação dos prazos; despachos de juízes sobre prisão; escuta telefônica e mandados de busca e apreensão; e, até mesmo, petições de defensores. Isso tudo com o aval dos carimbos e assinaturas que visam tornar esses registros, documentos de fé pública, isto é, com veracidade atestada pelo Estado.

Assim sendo, o inquérito policial, realizado pela polícia civil, circula (fisicamente) em todas as instâncias do SJC, inclusive judiciárias, antes de ser utilizado para fundamentar o oferecimento (ou não) de uma denúncia pelo membro do Ministério Público. Embora apresentado pela dogmática jurídica como instrumento de cunho puramente administrativo - visando apenas à denúncia -, por ser automaticamente entranhado ao processo, na prática, esse instrumento acaba tendo forte participação nos procedimentos que visam condenar ou absolver alguém (LIMA, 1989).

O inquérito policial, em nossa tradição jurídica, busca alcançar a "verdade real", identificando um culpado responsável pelo que aconteceu. Nessa busca, valese de procedimentos inquisitivos e sigilosos, algumas vezes ilegais, mas que se tornaram práticas institucionalizadas de produção da verdade policial (LIMA, 1989, 1999).

Na transposição dos resultados da investigação para o texto escrito, no qual o modelo do inquérito policial se alicerça, há uma forte preocupação com a formalidade dos procedimentos e com a clareza e coerência dos elementos a serem apresentados. Tal se verifica, por exemplo, quando relatos (especialmente tomadas de depoimentos ou oitivas), contendo pontos de vistas divergentes ou conflitantes sobre os "fatos", são dispostos lado a lado, de maneira a fazer emergir contradições e poder permitir a descoberta da "verdade" (VARGAS, 2000). Essa preocupação encontra-se também presente nos relatos dos investigadores ("comunicações de serviço"), onde buscam estabelecer conexões de sentido, articulando, de um lado, as informações que, na sua origem, encontravam-se dispersas e fragmentadas e, de outro, aquelas obtidas de forma sigilosa que, embora essenciais para permitir a conexão, não podem comparecer no texto. A mesma preocupação aparece no relatório final de uma investigação bem sucedida (isto é, relatada com o indiciamento do suspeito), confeccionado pelo delegado, visando apresentar, em um texto coerente e juridicamente orientado, o que foi que aconteceu e quem foi o culpado. Nunca é demais ressaltar, entretanto, que tal construção de sentido é elaborada sem a participação efetiva do 
contraditório e pode tomar diferentes direções, dependendo da condição do suspeito.

Mas o que nos interessa observar nessa construção, apresentada de maneira coerente e atenta à formalidade dos procedimentos (ainda que de forma cerimonial), é ser ela o produto de ações realizadas de maneira descoordenada e, não poucas vezes, sem atender à legalidade prevista. Nossa premissa é a de que, além de um alto grau de desarticulação das ações, prevalece também o descrédito do que foi realizado pelo outro e, às vezes, os conflitos de competência entre os diferentes operadores. Assim, é como se cada tipo de operador - agente policial, perito, escrivão, delegado, promotor, defensor, juiz -, quando voltado para os procedimentos de investigação, se valesse de uma lógica própria, com o "saber" e "poder" institucional que lhe é conferido (ou mesmo extrapolando-o) ${ }^{4}$ e, nesse mesmo movimento, atribuísse aos outros participantes dessa produção as falhas na descoberta da "verdade" buscada por todos.

Disjunção interorganizacional e intraorganizacional, conforme mostraremos para o caso da polícia, como também relações pautadas na falta de confiança, seriam compensadas pela obrigatoriedade da instauração do inquérito policial, instrumento que na prática, não se restringe apenas a constatar o fato e elucidar materialidade e autoria para subsidiar a ação penal, tal como o definem os textos jurídicos, mas procede efetivamente à formação da culpa do suspeito ao encadear os fatos de maneira coerente, de forma a fazer emergir "a verdade" do que aconteceu (MISSE, 2010; VARGAS \& NASCIMENTO, 2010).

Nele, constrói-se, assim, uma versão oficial do fato, traduzida para a linguagem jurídica, que irá acompanhar o processo, servindo de base não apenas para a denúncia, mas para todo o processamento subsequente, tornando-se, frequentemente, objeto de referência dos operadores durante a fase judicial: embasando decisões ou sendo contestado em razão dos meios ilícitos empregados na sua realização (LIMA, 1989). Desse modo, o inquérito possibilitaria uma junção frouxa das atividades empreendidas na polícia, bem como da organização policial com as outras organizações do SJC.

\section{O Sistema de Justiça Criminal frouxamente ajustado}

Até agora, viemos falando de junção frouxa sem delimitar o conceito. A ideia de que organizações são frouxamente ajustadas foi proposta pela abordagem institucionalista de Meyer \& Rowan (1977). Estes postularam, com base em pesquisas empíricas, que os elementos estruturais das organizações formais, que delimitam como e com que fins as atividades são feitas juntas, funcionam não como coordenação e controle, mas quase sempre são frouxamente ligados uns
4. A respeito da disputa de diferentes saberes na confecção do inquérito policial, ver Trindade, Spagna \& Maciel (2010). 
5. Nas palavras dos autores: "organizações formais são quase sempre frouxamente ajustadas: elementos estruturais são apenas frouxamente ligados uns aos outros, regras são freqüentemente violadas, decisões são constantemente não implementadas e, se implementadas, têm conseqüências incertas, tecnologias têm eficiência problemática e sistemas de avaliação e inspeção são subvertidos ou tornam-se tão vagos que permitem pouca coordenação" (MEYER \& ROWAN, 1977, p. 343).

6. Segundo Hagan et al (1979), o surgimento dos probation officers, agentes cuja função é investigar a personalidade e as situações social e legal do acusado e então, elaborar uma recomendação individualizada para a sentença, deu-se primeiro em departamentos de cortes juvenis americanas e depois em cortes de adulto. 0 propósito da criação desses departamentos foi decorrente do postulado do direito positivista de relacionar o castigo ao criminoso e não ao crime. aos outros. Assim, regras são violadas com frequência ou, se implementadas, têm consequências incertas e a avaliação e a inspeção são raras, de maneira a permitir uma vaga coordenação (MEYER \& ROWAN, 1977)5. Para os autores, essa característica de boa parte das organizações das sociedades modernas se deve à sua estrutura formal refletir a realidade construída socialmente como mitos do ambiente, muitas vezes reforçados pela opinião pública ou pela lei. Tais mitos são incorporados à estrutura da organização como regras cerimoniais, conferindo-Ihe legitimidade, mesmo quando são inconsistentes ou quando conflitam com o seu funcionamento efetivo. Para solucionar inconsistências e conflitos entre regras cerimoniais e efetividade, as organizações podem se valer de duas estratégias articuladas. Uma delas é a disjunção, de maneira a possibilitar a minimização dos conflitos. A outra são manifestações de confiança e de boa fé interna e externamente. Confiança nos mitos que justificam a existência da organização e pressuposição de que todos os participantes da organização agem de boa fé. Ambas as estratégias permitem evitar a inspeção e avaliação efetivas. Assim, a minimização dos conflitos e das disputas, gerados entre as regras formalizadas e a prática e entre as unidades dirigidas à atividade fim, é feita por meio de sua disjunção. A quebra da integração possibilita à organização legitimar sua estrutura formal, ao mesmo tempo em que suas atividades continuam respondendo às necessidades práticas que lhe são colocadas. No lugar de controle e avaliação, passa a prevalecer a lógica da confiança (MEYER \& ROWAN, 1977).

A análise organizacional de Meyer \& Rowan foi aplicada por Hagan e colegas (1979) ao Sistema de Justiça Criminal americano. Analisando a influência da atuação dos probation officers ${ }^{6}$ nos processos de decisão, eles observaram que a criação do subsistema de probation tem muito mais a ver com a fabricação de mitos legais do que com a reestruturação, de fato, dos processos de decisão. Os autores descrevem as prescrições da justiça individualizada como regras institucionalizadas incorporadas pelos tribunais criminais de forma a atender às suas necessidades de legitimação. Para estes, o sistema funciona, em relação à justiça individualizada, ora de forma integrada ora desintegrada. Quando as recomendações feitas pelos agentes de probation não conflitam com as demandas de eficiência do tribunal, prevalece a junção. Quando há conflitos, a disjunção é a forma encontrada para preservar o mito de individualização. A disjunção nos tribunais americanos realiza-se por meio da ampliação das cadeias de decisão. Assim, o papel do probation officer seria cerimonial, pois preserva o mito da individualização e confere legitimidade aos tribunais.

A referência ao grau de articulação ou disjunção das organizações do Sistema de Justiça Criminal brasileiro foi feita pela primeira vez por Edmundo Campos Coelho, em seu artigo seminal intitulado $A$ administração da Justiça Criminal no Rio de Janeiro: 1942-1967, publicado em 1986. Com base nessa série 
histórica de dados sobre inquéritos e processos por crimes e contravenções e na reconstituição do fluxo decisório do SJC no Rio de Janeiro, Coelho desenvolveu a hipótese da administração da Justiça Criminal ser constituída de "subsistemas frouxamente integrados"7. A disjunção ocorreria devido à lógica diferenciada prevalente em cada organização do sistema. Enquanto a polícia atua repressivamente buscando prender e indiciar indivíduos, promotores e juízes seguem outra lógica, que deve considerar não apenas limites probatórios, como também recursos e custos da repressão. Já um certo grau de junção seria obtido via papéis, também podendo ser alcançado por meio de receitas práticas profissionais ou de construção social de tipos (COELHO, 1986) ${ }^{8}$.

Iremos, neste artigo, aprofundar o insight de Coelho (1986) sobre "os papéis" e desenvolver a ideia de que o inquérito policial, em particular, permite algum grau de integração no SJC. Pode-se argumentar, também, acompanhando os achados mais recentes da literatura internacional sobre Justiça Criminal, que a disjunção do SJC, de fato, não se restringe ou, até recentemente, não caracterizava apenas o Sistema de Justiça Criminal brasileiro. Ao contrário, até os anos 1980, ela balizou boa parte dos Sistemas de Justiça Criminal no mundo, sendo a sua expressão mais visível o efeito de funil. Uma das razões da disjunção pode ser explicada no fato de os Sistemas de Justiça Criminal modernos terem sido compelidos a atender às demandas de pretensão do Estado Moderno de exercer o monopólio do controle do crime (GARLAND, 2008). Portanto, seguindo o esquema proposto por Meyer \& Rowan (1977), o "mito do estado soberano", como o denominou Garland (2008) foi incorporado aos SJCs modernos como regras institucionalizadas e a disjunção foi a forma encontrada para garantir a sua legitimidade, permitindo que esses sistemas atendessem, de um lado, à meta de controle do crime, perseguida de forma cerimonial (visto ser uma meta impossível de ser realizada) e, de outro, às necessidades práticas do sistema. O que, ao nosso ver, é particular ao Brasil e destoante do esquema proposto pela teoria das organizações (TO) é o fato de a disjunção não ser acompanhada de manifestações de confiança e boa fé. Muito pelo contrário, prevalece em nosso sistema a desconfiança entre os operadores responsáveis por administrar a justiça.

Foi o que observamos no estudo realizado em Belo Horizonte, especialmente no que se refere à relação estabelecida entre Polícia Civil (PC) e Ministério Público (MP) (VARGAS \& NASCIMENTO, 2010). Tanto pelo lado da PC, quanto pelo do MP, foi unânime, por ocasião da pesquisa, o reconhecimento de que existe hoje uma grande desarticulação entre os trabalhos realizados pelas duas instituições. De acordo com os operadores, a relação entre Polícia Civil e Ministério Público desenvolve-se, exclusivamente, através da troca dos documentos necessários ao atendimento das necessidades burocráticas dos inquéritos policiais. E o fato de a relação entre PC e MP se dar apenas através de "papéis" parece
7. Os trabalhos de Paixão (1982) sobre a polícia e de CoeIho (1986) sobre a Justiça Criminal foram os primeiros realizados no Brasil a partir de uma perspectiva organizacional. Ambos incorporam os achados de Meyer \& Rowan (1977) e de Hagan et al (1979).

8. Vargas (1999) identificou o Sistema de Justiça Criminal funcionando de forma relativamente articulada para certos tipos de estupradores e segundo a relação destes com a vítima.

9. Esse mito vigora no Brasil, mesmo que a pretensão do Estado ao monopólio da violência se dê de forma bastante incompleta. A respeito da forma, ver Adorno (2005). 
10. Quebras de sigilo telefônico e mandados de prisão devem passar pelo crivo do juiz, necessariamente. Também a ele compete a autorização para as dilações de prazos, a serem concedidas com $\mathrm{O}$ objetivo de dar continuidade às investigações inacabadas e consequente encerramento dos inquéritos para remessa ao Poder Judiciário.

11. Hoje em dia, o Ministério Público já realiza investigações criminais, embora a constitucionalidade dessa atuação ainda se encontre em debate. prejudicar sensivelmente a qualidade e a celeridade das investigações policiais e, consequentemente, das denúncias oferecidas pelo Ministério Público.

Embora a disjunção propicie a minimização do conflito na realização das atividades fins, já que o MP aceita passivamente o trabalho realizado pela polícia, tal desarticulação é, contudo, motivo de reclamação nas duas organizações. Pelo lado da Polícia Civil, a principal queixa dos operadores diz respeito ao afastamento que o Ministério Público mantém do trabalho de investigação. Delegados e agentes afirmaram que, salvo raríssimas exceções, o MP não desempenha com efetividade sua função de acompanhamento, orientação e controle das investigações, limitando-se a, simplesmente, ratificar todo o trabalho feito pela PC, tão logo este seja concluído. Já por parte do Ministério Público, os promotores admitem que, apesar de representarem a instituição titular da ação penal, praticamente não participam na orientação dos inquéritos policiais, tendo sua ação limitada à solicitação ocasional de algumas diligências complementares. Portanto, o relacionamento protocolar apenas via papel caracteriza a disjunção entre PC e MP.

Quanto aos juízes responsáveis, no inquérito policial, por autorizar todo e qualquer ato a ser praticado pela polícia que afete as liberdades e garantias individuais, a sua atuação, na prática, mostra-se tão cerimonial e desconectada do propósito de elucidação dos homicídios quanto a dos promotores ${ }^{10}$.

Entretanto, a disjunção dessas organizações não é acompanhada pela suposição de que todos estão agindo de boa fé, nem tampouco são relações de confiança que as permeiam, como postula a teoria das organizações (TO), mas, ao contrário, é o descrédito e a falta de confiança que balizam muitas das relações e, em particular, as relações entre a Polícia e o MP, instituições que cada vez mais assumem funções concorrentes ${ }^{11}$. Isso fica evidente nas falas dos integrantes do Ministério Público durante a realização da pesquisa em Belo Horizonte (VARGAS \& NASCIMENTO, 2010):

O que nós temos hoje é o seguinte, o delegado produz uma prova, ele não está preocupado se essa prova vai agradar, interessar o promotor. Ele pegou a prova como se fosse uma prova para o inquérito apenas e nada mais. Não há uma interlocução entre esse órgão investigativo com o órgão que é o titular da ação penal. (promotor de justiça)

(...) quando você tem um delegado que relata esse inquérito, e esse delegado não tem a credibilidade da sociedade, o que acontece? Essa prova do inquérito é imprestável. (promotor de justiça)

Então a prova do inquérito é boa? É, desde que aquela autoridade policial que presidiu o inquérito tenha credibilidade. Caso contrário, essa prova não vale nada. (promotor de justiça) 
A gente entra numa delegacia quando tem que entrar, os caras fecham a cara, os caras não aceitam. A dificuldade é muito grande a ponto de riscar o carro do promotor, de riscar o carro da Procuradoria, de quebrar o vidro do carro da Procuradoria. (promotor de justiça)

E nas falas dos integrantes da Polícia:

É muito difícil trabalhar em uma situação como a nossa. De estar trabaIhando com a mesma matéria que eles, mas ao mesmo tempo não sermos aliados. Eles nos veem e, acaba que a gente também os vê, como inimigos. Porque a sensação que nós temos é que eles querem nos prejudicar de alguma forma. (delegado de polícia)

Além do que, nós temos os promotores que chegam muito jovens, ainda muito imaturos. Normalmente, vêm de uma formação familiar que ofereceu a ele todas as facilidades possíveis, senão não teria passado no concurso. Então ele desconhece a dureza da vida. E como desconhecedor de tudo, ele acha que a caneta dele vai mudar o mundo, de acordo com os parâmetros cor de rosa que ele tem da existência. (delegado de polícia)

Uma outra perspectiva interpreta a visão negativa que tem da polícia o judiciário e vice-versa como resultado da posição hierárquica que assumem no sistema judicial (LIMA, 1989). Nessa abordagem, aliás, polícia e judiciário não são vistos como um sistema em que seus subsistemas respondem em maior ou menor grau uns aos outros, mas como um "mosaico de sistemas de verdade" (LIMA, 1999). Nele, as verdades se desqualificam umas às outras, com prejuízo para a verdade produzida na polícia, por ser esta situada em sua parte hierarquicamente inferior e orientada por critérios também considerados inferiores aos judiciais. Complementar ao sistema judicial e, não poucas vezes, estigmatizada por este, a polícia reagiria à visão negativa que tem dela o judiciário, positivando-a e invertendo-a em uma ética própria considerada superior (LIMA, 1989, 1999).

Uma explicação para a desconfiança institucional recíproca seria, portanto, a desigualdade entre polícia e judiciário ${ }^{12}$. Ela é pertinente para o entendimento das relações interorganizacionais, especialmente entre promotores e delegados, mas o é também para compreender a oposição existente, dentro da mesma organização, entre delegados e policiais ${ }^{13}$.

Essa oposição apareceu de várias maneiras na pesquisa realizada sobre o inquérito policial em cinco capitais brasileiras (MISSE, 2010). Verificou-se a disputa de saberes entre "tiras" (investigadores) e os delegados, materializada em "saberes policiais" e "saberes jurídicos". Isto é, policiais enfatizam a sua experiência de lidar cotidianamente com o crime, já delegados consideram o saber que detêm necessário à tradução dos resultados da investigação para a linguagem jurídica
12. Esta é ainda mais reforçada pela isonomia salarial dos promotores com os juízes e a sua não equivalência com os delegados.

13. Conforme a fala de um investigador: “Porque a polícia é muito assim. Isso aqui é uma monarquia onde os delegados são reis, entende. Tem rei bom e tem rei ruim". 
e ao controle das ações dos policiais, garantindo a sua legalidade (TRINDADE, SPAGNA \& MACIEL, 2010).

No estudo de Belo Horizonte (VARGAS \& NASCIMENTO, 2010), a função do delegado foi desqualificada pelos "tiras" como desnecessária, visto que limitada à tradução dos achados da investigação à linguagem jurídica e sem nenhum poder de decisão, já que perderam a prerrogativa de expedir mandados.

O delegado é necessário na hora de transformar uma coisa que é escrita ali, de forma coloquial, para uma outra coisa e mandar para o promotor. Agora se o promotor pegasse a comunicação coloquial e fizesse o que o delegado faz... o delegado é uma rainha da Inglaterra, só que do inquérito, quem decide é o promotor. (Agente policial)

Os delegados, por sua vez, são críticos em relação à postura dos agentes frente às atividades que desempenham. Ressentem-se da falta de comprometimento e de profissionalismo da categoria em geral e, embora sensíveis aos baixos salários que os policiais atualmente recebem, recriminam-nos pelo desempenho de atividades paralelas ("bicos"), especialmente pelos plantonistas, e por colocar o exercício profissional em segundo plano.

A pesquisa nacional verificou, também, disputas decorrentes de conflitos de interesses em razão da forma de progressão na carreira policial, encampadas pelos sindicatos das diferentes categorias de policial (MISSE, 2010). Agentes de polícia defendem uma carreira única que permita ao policial, em sua trajetória profissional, galgar distintos cargos em uma progressão vertical, até chegar a ser delegado.

Mas, mais do que constatar serem tais disputas decorrentes das diferentes posições dos operadores na hierarquia do Sistema de Justiça Criminal, interessa a esse estudo mostrar a extensão que pode assumir a disjunção e falta de confiança entre os diferentes tipos de operadores, por ocasião da atividade de investi-

14. Com diferentes significados, o conceito é central na teoria dos sistemas de Luhmann (1995), na teoria da estruturação de Giddens (1984) e, também, como vimos, no neo-institucionalismo de Meyer \& Rowan (1977).

15. À diferença de Schutz, Garfinkel introduz a noção de moralidade da ação. gação policial, para, em seguida, identificar como esta se torna possível.

\section{Confiança}

Mas, antes de fazê-lo, é necessário precisarmos melhor a noção de confiança utilizada no texto. Esse conceito, embora não seja novo na Sociologia, vem ganhando cada vez mais expressão e importância nas abordagens contemporâneas ${ }^{14}$. Entretanto, bem antes disso, a noção de confiança já era elemento essencial de certas correntes sociológicas, tais como a Sociologia Fenomenológica de Schutz (1979) e a Etnometodologia de Garfinkel $(1967)^{15}$. Para ambos, 
o conhecimento implícito (tácito) incorporado nas rotinas e nas práticas sociais é essencial para coordenar expectativas e interações. Do mesmo modo, e conforme a mesma lógica, a confiança que orienta expectativas é fundamental para a continuidade das interações. À falta desse mecanismo de coordenação de expectativas e comportamentos, pode corresponder a ruptura e a paralisação ${ }^{16}$. Outra alternativa seria a sua substituição por um mecanismo que desempenhe a mesma função.

Assim, é essa ideia de confiança - previsibilidade (absorção de incertezas) e boa vontade (premissa de que todo mundo age de boa fé) -, que será adotada pela teoria organizacional institucionalista de Meyer \& Rowan (1977). Centra-se nas expectativas mútuas sobre comportamentos futuros que permitem o controle e coordenação das atividades e dos subsistemas, em contexto de disjunção.

Retomando a premissa de um grau considerável de desarticulação dos subsistemas e de falta de confiança interorganizacional e entre os diferentes operadores que compõem o Sistema de Justiça Criminal brasileiro, interessa saber, então, como as atividades de investigação têm continuidade e não paralisam. Qual o mecanismo de coordenação alternativo à confiança que poderia estar atuando?

No próximo tópico iremos descrever uma investigação de homicídio dando ênfase particular a esse aspecto.

\section{A investigação de homicídio: uma análise descritiva}

Em geral, a intervenção estatal sobre um evento que pode ser criminalizado como homicídio inicia-se por um telefonema, seja de um transeunte, seja de um familiar ou de qualquer indivíduo que acione a polícia para "comunicar o fato". Nas palavras de um perito: "o crime começa quando o telefone toca. Tocou, pode saber: morreu um". A investigação de homicídios, entretanto, possui características muito particulares se comparada a outros tipos de investigação, isso porque a motivação para o seu cometimento vincula-se a uma complexa rede de relações interpessoais. Embora os procedimentos adotados não sejam diferentes daqueles utilizados em outros tipos de processos investigativos, como latrocínios e roubos, a natureza do evento exige uma grande capacidade de articulação das informações, a fim de construir uma cadeia de eventos coerente e minimamente fundada para a elucidação do delito.

A despeito, porém, da exigência de articulação, o que se percebe, na prática, é que os policiais - operadores responsáveis diretamente pela investigação policial - trabalham de maneira compartimentalizada com pouca ou nenhuma articulação entre si.

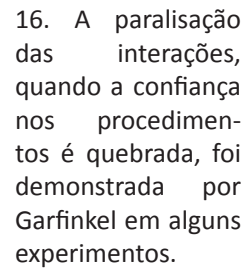


17. As investigações de homicídio subdividem-se em investigações preliminares e investigações de seguimento. A investigação preliminar compreende desde o acionamento das polícias, aos procedimentos efetuados na cena do crime e que ali se encerram quando a polícia deixa aquele lugar. Já a investigação de seguimento "ocorre após a polícia deixar o local e é feita tendo como ponto de partida os indícios ou provas obtidos na Investigação Preliminar. Pode durar dias, meses, ou mesmo não chegar a lugar algum" (MINGARDI, 2005, p.11).

18. Prova objetiva é todo e qualquer elemento físico constatado na área do crime: corpo da vítima e/ou agressor e local relacionado ao crime.
A polícia militar é, na maioria dos casos, o primeiro ator do sistema a ser acionado. É quem primeiro toma conhecimento do acontecido e quem primeiro chega ao local. Assim é que, chegando ao local-crime, compete aos policiais militares não somente a formulação do registro da ocorrência, bem como o isolamento do local (Art. 169 CPP), até que as equipes de perícia técnica e investigadores de plantão ${ }^{17}$ cheguem à cena do crime, após acionadas.

Aos peritos, compete o levantamento das provas objetivas ${ }^{18}$ no local-crime e, aos investigadores de plantão, cabem os levantamentos iniciais, tanto da vida pregressa da vítima como das possíveis testemunhas que, porventura, possam estar presentes no local ou em suas proximidades.

Na prática, contudo, uma série de dificuldades se interpõe nesse momento inicial. Os peritos, por exemplo, alegam que policiais militares definem como e quando acionarão os policiais civis, não isolam corretamente o local, descaracterizando-o e invalidando a coleta de vestígios, além de "negociarem" o registro do delito:

É por isso que todo mundo fala que perito demora. 'Nossa, tem duas horas que a PM tá aqui. Cadê a perícia, que tá demorando tanto?'. A gente simplesmente não foi acionado... Umas três horas depois que a PM tá lá é que a gente é acionado. Quando a gente chega eles já deitaram e rolaram. (perito criminal)

Você quer saber de verdade como é a PM na cena do crime? Então, vou te contar: eles chegam antes, interrogam as pessoas, escondem testemunhas, violam o local, roubam celular de vítima... Precisa falar mais? Você quer ver uma coisa interessante que acontece aqui na delegacia direto? Vira e mexe a gente recebe ofício da Polícia Militar pedindo para escutar fulano de tal, encaminhando objeto pra investigação. Uma coisa doida, porque eles não comunicam como acharam e ainda querem que a gente utilize aquilo no inquérito. Aí eu te pergunto: eu posso utilizar? Claro que não, né? De onde veio aquilo? Ninguém sabe, ninguém viu... (escrivão de polícia)

Agora, é assim: tem uma arma que foi encontrada numa poltrona, vamos supor. Aí quando a gente chega, o policial militar vira pra gente e diz: 'aqui doutora, peguei pra senhora. Ninguém mexeu, pode ficar tranquila'. Isso mata a gente. O cara já descaracterizou o local, entende? Aquilo já não pode ser mais usado como prova depois disso. Outro exemplo, o cara morre e é encontrado um estojo próximo a ele. Pela posição do estojo a gente sabe onde estava o atirador, entende? Se o estojo é removido dali, perdeu-se a prova. Não adianta ele chegar e dizer: 'olha, achei isso 
aqui'. Na mão dele não vale de nada. E outra, eles isolam o corpo e só o corpo, basicamente. (perita criminal)

Uma coisa muito interessante que você provavelmente não vai ver aqui com a gente e que acontece muito. A gente tá lá no local, né? Lembra daquele caso que acharam o corpo e ele tava todo queimado? Pois é. Daí a PM que tava preenchendo o boletim de ocorrência chegou perto de mim e disse: aqui, será que foi homicídio mesmo? Será que não dá pra registrar como suicídio? Pensa bem: um corpo queimado todo perfurado. (perita criminal)

Discordâncias dos peritos quanto ao proceder em relação ao isolamento da cena do crime, conflitos de competência, críticas e desconfiança quanto à legalidade do trabalho desenvolvido não são aspectos que se referem apenas aos policiais militares. Investigadores também se ressentem do trabalho do perito, limitado aos seus propósitos. Estes, por sua vez, criticam a atuação dos investigadores, dentre outras, pela maneira de juntar e interpretar as informações por eles fornecidas para proceder à comunicação do caso. Conflito de competência e disjunção do trabalho realizado apareceram claramente por ocasião de um acompanhamento de um local-crime, quando um investigador solicitou à pesquisadora em campo que perguntasse ao perito por que razão, afinal, a perícia técnica não produz fotos panorâmicas:

Escuta, por que você não pergunta para o pessoal da perícia a razão deles não tirarem fotos panorâmicas e ainda por cima impedirem a gente de tirar? Sabe por quê? Tem homicídio, e não é pouco caso não, em que o cara recebeu um monte de disparos no meio da rua, na esquina do bar, etc. e tal. Muitas vezes uma foto panorâmica mostra que o cara estava debaixo de uma casa e que a luz dessa casa estava acesa. Se a gente conta com uma foto dessas, pode ir até a casa do sujeito e quando ele disser pra nós que não viu nada a gente tem como provar: uai, mas ele foi assassinado debaixo da sua casa, sua luz estava acesa e foram mais de 4 disparos. Como o senhor não viu, nem escutou nada? (investigador de polícia)

Perícia cuida de provas objetivas. Objetiva vem de objeto, não é mesmo? Quem é o nosso objeto? É o corpo. Tudo o que estiver relacionado ao corpo é nossa responsabilidade e só nossa. Saiu do corpo? Responsabilidade da investigação. Essa coisa de foto panorâmica não é coisa nossa. (perito criminal)

Diversos estudos são unânimes em ressaltar a importância da investigação preliminar para que o crime de homicídio seja efetivamente apurado:

A regra é que o primeiro policial a atender a chamada tome algumas 
providências iniciais que são fundamentais para o bom andamento da investigação. (...) Um dos motivos disso é o tempo, que trabalha a favor do criminoso. Alguns falam em 24 horas, outros em 48 e os mais cautelosos consideram que em 72 horas as provas começam a desaparecer. Portanto, quanto mais rápido a polícia agir, maior é a probabilidade de esclarecimento do homicídio. (MINGARDI, 2005)

Portanto, uma boa investigação preliminar de homicídios pode ser caracterizada em função da gama de procedimentos adotados nos momentos seguintes ao acionamento da polícia. Em termos gerais, são elencados basicamente cinco fatores como definidores da qualidade de uma investigação preliminar: (1) a rápida chegada das equipes policiais ao local do fato; (2) o completo isolamento e a preservação adequada da cena do crime; (3) a realização de rápidas "diligências" nos arredores do local do delito para tentativa de prisão do autor do homicídio; (4) o rápido arrolamento de testemunhas presenciais e circunstanciais do fato (que devem ser dedicadamente entrevistadas ou ouvidas ainda no local do crime); (5) acompanhamento detalhado de todas as perícias que são realizadas no local do crime e no corpo da vítima (perinecroscópicas) (MINGARDI, 2005 apud VARGAS \& NASCIMENTO, 2010).

Com base na observação feita em campo e nas entrevistas com os operadores, verificou-se, entretanto, que a investigação preliminar "real", em geral, em nada corresponde à investigação "ideal", caracterizando a disjunção entre estruturas e as atividades. Policiais militares descaracterizam o local e, às vezes, "desaparecem" com os objetos da cena do crime. Peritos só são acionados pela PM muito depois de ocorrido o homicídio e limitam-se ao exame do corpo e aos poucos vestígios encontrados dentro do isolamento reduzido, como projéteis e estojos de balas. Investigadores de plantão, que não conhecem a dinâmica da criminalidade local, costumam lá chegar após a realização da perícia. Atuam independente da perícia ou valendo-se de informações preliminares colhidas por esta. Além disso, procuram localizar testemunhas ou parentes da vítima, que, muitas vezes, já não fornecem mais a versão primeira do ocorrido.

Pode-se, com tudo isso, imaginar a qualidade da matéria obtida nessa fase fundamental da investigação, quando prevalece a morosidade nos primeiros procedimentos adotados, pouquíssima cooperação entre os operadores, entendimentos diferenciados sobre o que deve ser o trabalho no local do crime e uma atmosfera de falta de confiança. Tanto a expectativa, quanto o comportamento dos outros nos procedimentos tomados, tal como deveriam ser, não é atendida, como também, a legalidade desses procedimentos é questionada. Mais do que isso, é como se já se esperasse um comportamento institucional desviado. Não se trataria, então, apenas de falta de confiança entre operadores institucionais, mas de desconfiança. Essa é, certamente, uma pista a ser seguida em futuros 
trabalhos.

Frente a isso, caberia novamente perguntar: Como então é possível uma investigação criminal ser levada a cabo em um contexto de disjunção entre regras e atividades em que a confiança não funciona como mecanismo de coordenação dos trabalhos e no qual prevalece a desconfiança?

\section{A investigação por meio do inquérito policial}

Os resultados dessa fase preliminar são transcritos para as peças que irão integrar o inquérito policial. São elas: os boletins de ocorrência elaborados por policiais militares, as comunicações de local, os laudos periciais, os autos de flagrantes, quando ocorrem, e as portarias.

Na transposição dos resultados da investigação para o inquérito policial, as práticas descoordenadas e, às vezes, ilegais vão dar lugar a registros escritos, preocupados com articulação de sentido, clareza, convencimento e com a coerência entre eles, nem sempre conseguida.

As peças seguintes são todas produzidas na e pela investigação de seguimento. Na visão dos policiais, a forma como ela é processada e conduzida é determinante para a definição de um inquérito como bom ou ruim.

Assim, encerrada essa etapa preliminar, após dez dias, aproximadamente, delegados, escrivães e a equipe que realmente investigarão aquele homicídio, terão acesso ao inquérito, contendo a portaria ${ }^{19}$ e a comunicação de local ${ }^{20}$. Isso ocorre porque a equipe que iniciou as investigações é uma equipe de investigadores que trabalha em regime de plantão. Ademais, a portaria que instaura um inquérito não é direcionada de imediato à delegacia responsável. Ela passa antes por um setor geral e, até que chegue à equipe responsável pela condução do processo investigatório, já se passaram, aproximadamente, sete ou dez dias da ocorrência do homicídio.

$\mathrm{Na}$ tentativa de escapar dessa burocracia e ganhar tempo, alguns investigadores de seguimento habituaram-se a fazer consultas diárias aos sistemas de informação policial, para monitorar os homicídios ocorridos no dia e noite anteriores. Isso é possível porque as informações preliminares dos boletins de ocorrência referentes a esses homicídios são disponibilizadas nos sistemas policiais no mesmo dia do fato.

A partir desse momento, adotando um comportamento discricionário, os investigadores de seguimento selecionam os casos a serem investigados. Casos por estes classificados como de fáceis elucidação terão sua investigação iniciada

19. O flagrante ocorre sempre que o suposto criminoso é capturado em ato contínuo à deflagração do crime. Caso ocorra, é elaborado um documento (auto de flagrante), no intuito de documentar a prisão feita. Em não havendo flagrante, isto é, na maior parte dos homicídios ocorridos, "lavra-se" uma portaria que é a peça inaugural do inquérito, ou seja, um documento que relata brevemente os trabalhos iniciais da investigação preliminar (comunicação, remoção do corpo da vítima, etc.) e solicitam-se medidas de investigação de seguimento.

20. Comunicação de local é o documento produzido pela equipe de investigadores que terá o primeiro contato com a cena do crime, direcionado ao delegado com vistas à formulação da portaria e consequente utilização por parte das equipes de investigação de seguimento. 
21. A expressão refere-se ao vai e vem dos inquéritos entre a polícia e o judiciário ou, mais recentemente, entre a delegacia e as centrais de promotores responsáveis pela apreciação dos inquéritos ainda não finalizados.

22. Isso deve-se às relações conflitivas entre operadores da organização policial e peritos, porque esses últimos não se consideram policiais.

23. Na pesquisa realizada em Belo Horizonte, identificamos a importância dada aos depoimentos de suspeitos e de testemunhas para o sucesso da apuração feita nos inquéritos de homicídio. Isso nos levou à conclusão de que o procedimento do inquérito se restringe a uma prática quase que estritamente cartorial onde pouca ou nenhuma ênfase é conferida à investigação por meio de provas técnicas (VARGAS \& NASClMENTO, 2010). antes mesmo que o inquérito, com a portaria e comunicação de local, chegue fisicamente às mãos dos delegados e escrivães dos cartórios de delegacias responsáveis. Já os casos categorizados como difíceis aguardarão o recebimento do inquérito para que se dê início às investigações e, dependendo do volume de inquéritos na delegacia, serão preteridos em detrimento daqueles já em andamento, engrossando a fila dos inquéritos que ficarão no "pingue-pongue"21 e, no decurso do tempo, por falta de provas, serão arquivados (MISSE, 2010).

Percebe-se que a desarticulação continua a se manifestar na investigação de seguimento. Um exemplo disso é a disjunção entre os trabalhos periciais e aqueles realizados por esse tipo de investigação. Ambos correm em paralelo, sem que haja uma real troca de informações ${ }^{22}$. Nem mesmo o delegado utiliza-se dos laudos para fazer os relatórios finais dos inquéritos, visto que, em geral, esses são anexados ao inquérito já praticamente concluído. Com isso, as investigações terminam por se pautar quase que exclusivamente pela coleta de provas denominadas subjetivas: interrogatórios do suspeito, depoimentos em cartório de testemunhas, etc. ${ }^{23}$

Como todos os procedimentos investigativos adotados pelos policiais precisam ser transpostos de forma escrita e atender às formalidades jurídicas exigidas pelo modelo de investigação do inquérito policial, esse termina por "empoderar" não apenas o delegado, responsável pela sua condução, como também os funcionários que realizam os procedimentos cartorários, com destaque para o escrivão de polícia. Isso porque o escrivão assume papel fundamental, tanto no processo de formação da culpa do suspeito, como na própria condução do inquérito (VARGAS \& NASCIMENTO, 2010). Em geral, é ele e não o delegado que, na prática, maneja o instrumento, de maneira a ordenar o que se apurou em textos apresentados com um mínimo de coerência e buscando atender às exigências formais e burocráticas.

Mas daqui a pouco você está sabendo fazer o serviço melhor que o delegado. Isso aí é uma realidade. Na prática, tem delegado que pede comunicação final depois de inquérito, daí copia e cola. Só pra fazer relatório. Oficialmente não. Você não tem a menor qualificação pra fazer aquilo ali. Mas na prática é o que acontece. A gente acaba aprendendo. Não tem jeito. Isso aí chega ao ponto do delegado chegar pra você e falar: e aí, o que você acha que tem que fazer? Você vê que o cara está perdido... Aí eu digo: 'Mas o presidente do inquérito é você! Quem tem que decidir é você. Não sou eu não'. (escrivães sobre delegados, retirado dos grupos focais realizados para o estudo "O inquérito Policial: uma pesquisa empírica").

Assim, se a decisão e o trabalho de articulação próprios dessa fase recaem mais sobre o escrivão do que sobre o delegado, essa prerrogativa ou poder não lhe 
pertencem nem de direito nem de fato, antes emana do modelo do inquérito policial e do papel de coordenação e controle que este desempenha no processo de investigação criminal.

A regra é o escrivão desde quando ele (o inquérito policial) começa. Aí aparece uma nova evidência, o escrivão é que vai lá e já começa a iniciar. Por exemplo, eu ouvi o fulano aí ele falou assim: ah não, quem esteve envolvido também foi o sicrano. Então o escrivão não espera o delegado fazer, ele já vai lá e já procede a intimação. Pra que? Pra poder prosseguir na coisa. Então o delegado praticamente só leu o inquérito no início e no final e assina. Ele tem que confiar no escrivão dele. (escrivães sobre delegados, retirado dos grupos focais realizados para o estudo "O inquérito Policial: uma pesquisa empírica").

Nessa fase em que as relações de dependência para se realizar o trabalho imposto pelo instrumento e pela exigência de produtividade são maiores, a necessidade de cooperação termina por gerar relações de confiança que, por sua vez, contribuem para a coordenação das atividades.

Eu tenho uma média de 800 inquéritos sob meu poder na delegacia hoje. É impossível acompanhar de perto cada um deles. Como é que eu vou fazer oitiva de 700, 800 inquéritos? Impossível! Se eu não delegar, eu tô frito. Fazendo só portaria e relatório, eu já não consigo relatar inquérito suficiente. É por isso que eu digo: delego mesmo. Já falo com escrivão e agente: irmão, aqui é tudo dividido. Cada um faz sua parte. (delegado de polícia)

\section{Confiança, poder e coordenação}

Mas se, em maior ou menor medida, a confiança não está ausente das relações intra e interorganizacional, ela é construída, entretanto, muito mais como decorrência das relações pessoais do que de rotinas e padrões impessoais e burocráticos de relacionamento dentro da organização policial e entre as organizações do Sistema de Justiça Criminal.

Relações de "proteção" e "lealdade" entre o delegado titular e os policiais são muito visíveis, conforme pudemos observar na pesquisa em Belo Horizonte, assim como observamos o peso das relações pessoais entre delegados e promotores ou promotores e juízes, acionadas para a realização do trabalho fora dos trâmites burocráticos. Mas não se trata aqui de relações de "confiança", tal como entendemos até agora, isto é, confiar que o trabalho será realizado, que se está agindo de boa fé e que funciona como mecanismo de controle institucional, mas de relações pessoais que envolvem proteção, trocas e favores, tipicamente 
hierárquicas (VARGAS \& NASCIMENTO, 2010).

Segundo alguns desenvolvimentos mais recentes da TO, o poder é um mecanismo similar à confiança, garantindo também a previsibilidade e coordenação das ações. Um e outro governam ou dominam as relações inter e intraorganizacionais e ambos funcionam como controle social (BACHMANN, 1999).

No Brasil, a atividade de investigação e as relações entre aqueles que dela participam são coordenadas pelos procedimentos burocráticos instituídos pelo inquérito policial. Esses procedimentos têm proeminência sobre a investigação, tornando-se, em sua forma mais extrema e não incomum, a própria atividade fim da organização policial. Tal coordenação funciona porque, dentre outras coisas, sob sua ausência paira a ameaça de sanção. Daí a prevalecer na investigação, sob o modelo do inquérito policial, a preocupação com o atendimento dos prazos e dos procedimentos formais.

O modelo do inquérito policial encarna o Estado que pretende o controle do crime e do criminoso, mas que se quer também especialmente vigilante sobre as ações daqueles que o representam. É esse poder do instrumento que, ao nosso ver, permite algum grau de coordenação e controle das relações do SJC e, mais exatamente, daquelas estabelecidas na fase policial.

\section{Notas conclusivas}

O aumento da criminalidade violenta, nos últimos 30 anos no Brasil, concorreu para diminuir ainda mais a efetividade do SJC, que já era baixa (MISSE \&VARGAS, 2009). Esse quadro foi agravado com novas modalidades de crimes, um volume cada vez maior de inquéritos policiais e a morosidade crescente no processamento desses, levando à perda de legitimidade do SJC dentro e fora do sistema. É nesse contexto que o inquérito policial também vem perdendo legitimidade e um acalorado debate e várias propostas de reforma ou de extinção desse instrumento vêm sendo aventadas. Trata-se de um desafio de grandes proporções, tendo em vista que, entre os operadores que o manejam, não se imagina a investigação sem o recurso desse modelo ou, não poucas vezes, não se consegue sequer distinguir a investigação criminal do inquérito policial.

Mudanças organizacionais de cunho gerencial vêm sendo propostas e realizadas em alguns Estados brasileiros, especialmente no subsistema de segurança pública, visando aumentar a sua eficiência e, em decorrência, a articulação entre os setores organizacionais que operam, como vimos, apartadamente. Contudo, tais mudanças não tocam nessa velha estrutura, limitando-se a adotar metas para aumentar a sua produção. 
Apesar do desejo de mudança, diversos fatores concorrem para a manutenção do inquérito policial. Em primeiro lugar, o aferramento do delegado a esse instrumento que justifica a existência da função que lhe confere poder. A obstinação dessa categoria funcional por esse modelo de investigação faz-se particularmente visível no lobby que exerce no Congresso Nacional para garantir a sua permanência com o menor número de modificações possíveis. Não é a toa que, há mais de dez anos, ali tramitam propostas de simplificação da investigação criminal e outros tópicos a ela concernentes sem nenhum resultado.

Em segundo lugar, conforme demonstramos na apresentação dos resultados da pesquisa realizada em Belo Horizonte, o inquérito policial, por privilegiar a confissão do suspeito, é meio decisivo para fazer progredir o processo de formação da culpa, em busca da "verdade real". Por isso, a proposta prevista para a simplificação da fase investigativa, corre o risco de encontrar sérias resistências e de não ser incorporada às práticas dos responsáveis pela condução do inquérito (VARGAS \& NASCIMENTO, 2010).

Em terceiro lugar, como buscamos aqui mostrar, com o auxílio da análise organizacional, o inquérito policial desempenha um papel crucial de articulação das atividades dos operadores da fase de investigação policial (que, como vimos, atuam seguindo, alterando ou desviando-se das regras estabelecidas ou criando regras próprias). De um lado, ele permite que a investigação criminal seja apresentada como ela deveria ser e não como foi realizada efetivamente (de forma cerimonial). De outro, restringe e sanciona o comportamento dos operadores, de forma a conseguir algum grau de cooperação e controle das ações realizadas, cooperação esta obtida muito mais por meio de relações construídas a partir de contatos pessoais, do que aquelas decorrentes de comportamentos de rotina padronizados.

Pode-se pensar, por fim, a dificuldade que representa a transformação ou eliminação de um instrumento que reproduz a ordem social brasileira. Ordem esta que tem como uma das suas principais marcas a distância entre os dispositivos previstos nas leis (Estado) e as práticas efetivas (Sociedade) e a desconfiança em relação a essas práticas.

Abstract: This article draws on the hypothesis that the Brazilian Criminal Justice System is loosely coupled and that police inquiry, as an obligatory procedure, fulfils the role of establishing some degree of coordination of police activities and between the organizations of the Criminal Justice System. The validity of this instrument is challenged when belief in the capacity of the State to control crime is heavily shaken and replaced by demands for efficiency and greater coordination in the administration of justice. Despite the desire for change, various factors come into play to maintain this investigative model. 
Keywords: Police Inquiry, Criminal Justice System, Police, Organization Theory.

\section{Referências Bibliográficas}

Adorno, Sérgio (2005) "Le monopole étatique de la violence: le Brésil face à I’héritage occidental”. Cultures \& Conflits. Introduction n59. 3: 149-174.

Bachmann, Reinhard (1999) "Trust, power and Control" in Trans-organizational Relations. ESRC Centre for Business Research, University of Cambridge Working Paper n. $129: 1-47$

Bittner, Egon (2003) Aspectos do trabalho policial. São Paulo: Edusp.

Beato Filho \& Cláudio Chaves (1992) "Definição de um fato: homicídio ou suicídio?". Análise \& Conjuntura. Vol. 07, n. 2 e 3, maio/dez.

Código De Processo Penal - Gomes, Luis Flávio (org) (2004) Revista dos Tribunais. 6ạ. Edição atualizada em 05 de janeiro [Primeira edição 1942].

Coelho, Edmundo Campos (1986) "A Administração da Justiça Criminal no Rio de Janeiro: 1942-1967". Dados - Revista de Ciências Sociais, vol. 29, no. 1: 61-81. Instituto Universitário de Pesquisas do Rio de Janeiro (IUPERJ).

Garfinkel, Harold (1967) Studies in Ethnometodology. New Jersey: Prentice Hall. Garland, David (2008) A Cultura do Controle. Crime e ordem social na sociedade contemporânea. Rio de Janeiro: Revan.

Grinover, Ada Pellegrini (1998) O Processo em Evolução. 2ed. Rio de Janeiro: Forense Universitária.

Giddens, Antony (1984) The Constitution of Society. Cambridge: Polity.

Hagan, J., Hewit, J. D. \& Alvin, D. F. (1979) “Cerimonial justice: crime and punishment in a loosely coupled system". Social Forces, v. 58, n. 2: 506-527.

HAGAN, John (1989) "Why is there so little criminal justice theory?". Journal of Research in Crime and Delinquency, vol.26, n.2, May: 116-135.

Lima, Roberto Kant (1989) “Cultura Jurídica e Práticas Policiais: a tradição inquisitorial". Revista Brasileira de Ciências Sociais. São Paulo, ANPOCS, vol. 4, n. 10: 65-84.

(1994) A polícia da cidade do Rio de Janeiro - Seus dilemas e paradoxos. Rio de Janeiro: Polícia Militar do Rio de Janeiro. 
(1999) "Policia, Justiça e Sociedade no Brasil: Uma abordagem comparativa dos Modelos de Administração de Conflitos no Espaço Público". Revista de Sociologia e Política. UFPR, Curitiba, vol. 13: 23-38.

(2008) "Ensaios de Antropologia e de Direito: acesso à justiça e processos institucionais de administração de conflitos e produção da verdade jurídica em uma perspectiva comparada" in Coleção Conflitos, Direitos e Cultura. Rio de Janeiro: Lúmen Júris.

Lopes Jr, Aury (2006) Sistemas de Investigação Preliminar no Processo Penal. 4 Edição Rio de Janeiro: Lumens Juris.

Luhmann, Niklas (1995). Social Systems. Stanford: Stanford University Press, Marinho, Karina L. R. (2011) As Organizações Policiais e os Processos de Transição entre Modelos. Mitos, Racionalidade e o Campo Institucional da Polícia. Tese de Doutorado Universidade Federal de Minas Gerais.

Meyer, John W. \& Rowan, Brian (1977) "Institutionalized Organizations: formal structure as myth and ceremony". American Journal of Sociology, vol. 83, n. 2, september: 440-63.

(1991) Institucionalized organizations: Formal structure as myth and cerimony in the new institucionalism in organizational analysis. Chicago, University of Chicago Press.

Mingardi, Guaracy (s/d) Tiras, Gansos e Trutas. Segurança Pública e Polícia Civil em São Paulo. São Paulo: Corag - Coleção Estado e Sociedade.

Misse, Michel (2008) "Sobre a construção social do crime no Brasil: esboços de uma interpretação" in Michel Misse (org.), Acusados e Acusadores: estudos sobre ofensas, acusações e incriminações. Faperj/Revan. Rio de Janeiro.

(org.) (2010) O Inquérito Policial no Brasil - Uma Pesquisa Empírica. Rio de Janeiro: Booklink/FENAPEF/NECVU.

Misse, Michel. \& Vargas, Joana. D. (2009) "A produção decisória do sistema de justiça criminal no Rio de Janeiro ontem e hoje: um estudo preliminar". Revista Brasileira de Ciências Criminais, vol. 77: 237-260.

Paixão, Antônio Luiz (1982) "A Organização Policial numa Área Metropolitana". Dados - Revista de Ciências Sociais, IUPERJ, vol. 25, n. 1: 63-85.

Ratton, José Luiz (2007) “Aspectos organizacionais e culturais da violência policial" in J. L. Ratton \& M. Barros, Polícia, Democracia e Sociedade. Rio de Janeiro: Lumen júris. 
Sadek, Maria Tereza (org) (2003) Delegados de Polícia. São Paulo: IDESP/Editora Sumaré e Fundação Ford.

Schutz, Alfred (1979) Fenomenologia e Relações Sociais. [Organizador: H. Wagner], Rio de Janeiro: Zahar.

Trindade, Arthur; Spagna, Laiza \& Maciel, Wellington C. (2010) “A Discricionariedade no Sistema de Justiça Criminal: Uma Análise do Inquérito Policial no Distrito Federal" in Michel Misse (org.), O Inquérito Policial no Brasil - Uma Pesquisa Empírica. Rio de Janeiro: Booklink/FENAPEF/NECVU.

Vargas, Joana Domingues (1999) "Familiares ou desconhecidos? A relação entre os protagonistas do estupro no fluxo do Sistema de Justiça Criminal". Revista Brasileira de Ciências Sociais, vol. 14, n. 40, junho: 63-82.

(2000) Crimes Sexuais e Sistema de Justiça. São Paulo, IBCCrim.

(2007) "Análise comparada do fluxo do sistema de justiça para o crime de estupro". Dados - Revista de Ciências Sociais, v. 50: 671-697.

Vargas, Joana Domingues \& Nascimento, Luís Felipe Zilli (2010) “Uma abordagem Empírica do Inquérito Policial: O caso de Belo Horizonte" in Michel Misse (org.), O Inquérito Policial no Brasil - Uma Pesquisa Empírica. Rio de Janeiro: Booklink/FENAPEF/NECVU, 102-190. 